\title{
Diagnosis of processes controlling water vapour in the tropical tropopause layer by a Lagrangian cirrus model
}

\author{
C. Ren $^{1}$, A. R. MacKenzie ${ }^{1}$, C. Schiller ${ }^{2}$, G. Shur ${ }^{3}$, and V. Yushkov ${ }^{3}$ \\ ${ }^{1}$ Environmental Science Department, Lancaster University, Lancaster, UK \\ ${ }^{2}$ Forschungszentrum Jülich, Germany \\ ${ }^{3}$ Central Aerological Observatory, Dolgoprudny, Russia
}

Received: 23 March 2007 - Published in Atmos. Chem. Phys. Discuss.: 25 April 2007

Revised: 6 August 2007 - Accepted: 9 October 2007 - Published: 18 October 2007

\begin{abstract}
We have developed a Lagrangian air-parcel cirrus model (LACM), to diagnose the processes controlling water in the tropical tropopause layer (TTL). LACM applies parameterised microphysics to air parcel trajectories. The parameterisation includes the homogeneous freezing of aerosol droplets, the growth/sublimation of ice particles, and sedimentation of ice particles, so capturing the main dehydration mechanism for air in the TTL. Rehydration is also considered by resetting the water vapour mixing ratio in an air parcel to the value at the point in the 4-D analysis/forecast data used to generate the trajectories, but only when certain conditions, indicative of convection, are satisfied. The conditions act to restrict rehydration of the Lagrangian air parcels to regions where convective transport of water vapour from below is significant, at least to the extent that the analysis/forecast captures this process. The inclusion of hydration and dehydration mechanisms in LACM results in total water fields near tropical convection that have more of the "stripy" character of satellite observations of high cloud, than do either the ECMWF analysis or trajectories without microphysics.

The mixing ratios of total water in the TTL, measured by a high-altitude aircraft over Brazil (during the TROCCINOX campaign), have been reconstructed by LACM using trajectories generated from ECMWF analysis. Two other Lagrangian reconstructions are also tested: linear interpolation of ECMWF analysed specific humidity onto the aircraft flight track, and instantaneous dehydration to the saturation vapour pressure over ice along trajectories. The reconstructed total water mixing ratios along aircraft flight tracks are compared with observations from the FISH total water hygrometer. Process-oriented analysis shows that modelled cirrus cloud events are responsible for dehydrating the air parcels coming from lower levels, resulting in total water mixing ratios as low as $2 \mu \mathrm{mol} / \mathrm{mol}$. Without adding water back to some
\end{abstract}

Correspondence to: R. MacKenzie

(r.mackenzie@lancaster.ac.uk) of the trajectories, the LACM and instantaneous-dehydration reconstructions have a dry bias. The interpolated-ECMWF reconstruction does not suffer this dry bias, because convection in the ECMWF model moistens air parcels dramatically, by pumping moist air upwards. This indicates that the ECMWF model captures the gross features of the rehydration of air in the TTL by convection. Overall, the ECMWF models captures well the exponential decrease in total water mixing ratio with height above $250 \mathrm{hPa}$, so that all the reconstruction techniques capture more than $75 \%$ of the standard deviation in the measured total water mixing ratios over the depth of the TTL. By picking up the main contributing processes to dehydration and rehydration in the TTL, LACM reconstructs total water mixing ratios at the top of the TTL, close to the cold point, that are always in substantially better agreement with observations than instantaneous-dehydration reconstructions, and better than the ECMWF analysis for regions of high relative humidity and cloud.

\section{Introduction}

A better understanding of dehydration mechanisms in the Tropical Tropopause Layer (TTL) is important for the interpretation of changes in stratospheric water vapour, which may be one of the factors affecting the ozone layer and climate. The dryness of the stratosphere is maintained by the Brewer-Dobson circulation, in which, "air enters the stratosphere at the equator, where it is dried by condensation, travels in the stratosphere to temperate and polar regions, and sinks into the troposphere" (Brewer, 1949). Based on temperature observations at $100 \mathrm{hPa}$, Newell and Gould-Stewart (1981) narrowed the area where air enters the stratosphere to the region over the western Pacific, northern Australia, Indonesia, and Malaysia in the November-March period and over the Bay of Bengal and India during the Monsoon, and termed each of these areas a "stratospheric fountain".

Published by Copernicus Publications on behalf of the European Geosciences Union. 
Dessler (1998) argued that the "stratospheric fountain" hypothesis is not necessary, but Vomel and Oltmans (1999) argued that it was because Dessler (1998) used the tropical tropopause temperatures in the coldest period. Later, Sherwood (2000), using the operational wind data, found that air near the tropopause over the maritime continent (Indonesia) region is descending on average during both summer and winter. The simulation of Hatsushika and Yamazaki $(2001,2003)$ supports the existence of the stratospheric "drain" hypothesised by Sherwood (2000). Holton and Gettelman (2001) used horizontal advection to reconcile the apparent downward motion and the dehydration of the stratosphere, and referred to the region as "cold trap". This work inspired several Lagrangian studies e.g. Gettelman et al. (2002); Bonazzola and Haynes (2004); Jensen and Pfister (2004); Fueglistaler et al. (2004, 2005), which treated the removal of water from the trajectories in a variety of ways. In particular, Gettelman et al. (2002) used a set of 4 prescribed parameters (three timescales and one critical relative humidity) to describe the cloud microphysics that takes place in an air parcel. Although the prescribed parameters might not be appropriate to a wide range of specific air parcels represented by trajectories, the sensitivity to the parameters - with differences of up to $1 \mu \mathrm{mol} / \mathrm{mol}$ in final mean water abundance in some regions - does show the sensitivity of tropopause water vapour mixing ratios to cloud microphysics. Jensen and Pfister (2004) ran a detailed microphysical model in temperature curtains along isentropic trajectories. The use of temperature curtains makes the simulation more like multiple runs of a one-dimensional model, rather than a genuinely Lagrangian approach. The obvious lack of vertical shears of the horizontal winds used hinders its application to any specific observation. Although Jensen and Pfister (2004) showed that air entering the stratosphere may contain $\sim 10-40 \%$ more than the minimum saturation mixing ratios experienced by parcels, the minimum saturation mixing ratio has still been used frequently in recent assessments of the entry-level of stratospheric water vapour, since no other technology has been developed to take the microphysics into consideration along trajectories.

Our aim is to validate a Lagrangian Air-parcel Cirrus Model (LACM) using in-situ observations, and then use the model to assess the entry-level mixing ratio of stratospheric water vapour. In order to improve our understanding on the role of tropical cirrus clouds, more observations are necessary, especially in situ measurements, which are difficult to obtain, because of the altitude tropical cirrus clouds can reach. The high-altitude aircraft Geophysica is one of the very few aircraft that can fly at and above the tropical tropopause, making in-situ measurements (Stefanutti et al., 2004). This aircraft was deployed, along with the Falcon of the Deutsches Zentrum fur Luft- and Raumfahrt (DLR) and a Bandierante aircraft operated by IPMET (Instituto de Pesquisas Meteorológicas) in the TROCCINOX campaign, based in Sao Paolo state, Brazil, in January-March 2005
(Sect. 3.2, below). During the measurement campaign, in response to requests from those developing aircraft flight plans, LACM was also used in a test-prognostic mode to make cirrus clouds and water vapour forecasts (see http: //www.es.lancs.ac.uk/tropical-cirrus/campaigns/AMMA/ for the latest forecast products).

In this paper, we describe the model we have devised to diagnose the processes which control water vapour in the TTL, and we give case-study results. Our diagnosis is made by pair-wise comparisons between four sets of results: the new model, the underlying meteorological analysis driving the model, the simplest possible treatment of water vapour removal along trajectories, and in-situ total water measurements. In the next section, we describe the coupling of the microphysical parametrization to trajectories. The results and their comparison with observations are shown in Sect. 3, after which we give some conclusions.

\section{Parameterised microphysics coupled to trajectories}

The trajectories we used in this study were from different sources, but all based on ECMWF data. Forecast trajectories were calculated by ETH (Wernli and Davies, 1997). Backward trajectories released along flight tracks were calculated using FLEXTRA (Stohl, 1999). All the rest were from another offline trajectory model (Methven, 1997; Jackson et al., 2001). The intercomparison of Stohl et al. (2001) shows that the difference between different models is smaller than errors caused by inaccuracies in the wind fields or insufficient temporal and spatial resolution of the data set. So availability simply determined which trajectory code we used. In generating trajectories, the vertical velocity from ECMWF is directly used. Although the model-output vertical velocity fields, especially the assimilated fields, are noisier than the diabatic-heating-driven vertical velocity fields, this should not be a problem, as the noise produces effects similar to those produced if sub-grid vertical velocity fields were included. The precise influence of vertical velocity on results from our cirrus parameterisation has been discussed in Ren and MacKenzie (2005), and the sensitivity of trajectory models to vertical transport method discussed in Harris et al. (2005).

Along a trajectory, total water mixing ratio, $q_{t}$, is the sum of water vapour mixing ratio, $q_{v}$, and the equivalent ice content mixing ratio, $q_{i}$,

$q_{t}=q_{v}+q_{i}$,

here the mixing ratio is by mass, i.e., specific humidity or its equivalent. The definitions of the symbols used here and below are summarised in appendix A. The conservation of total water is

$\frac{d q_{t}}{d t}=D+R$ 
where $D$ is the dehydration rate, and $R$ is the rehydration rate.

Dehydration is through the sedimentation of ice particles. Processes associated with dehydration are described in the following three subsections, and are then followed by a description of the processes involved in rehydration.

\subsection{Deposition/sublimation}

The mass transfer between water vapour and ice particles is through the deposition/sublimation process. If $m$ and $r$ are the mass and radius of an ice particle (which we shall assume is spherical), $m$ changes when the particle is growing or evaporating,

$\frac{d m}{d t}=4 \pi r D_{v}\left(\rho_{v}-\rho_{s}\right)$

where $D_{v}$ is the diffusivity of water vapour in air, and $\rho_{x}$ is the mass concentration of water in the vapour phase $(x=v)$ and at the particle surface $(x=s)$. We assume that the water vapour mixing ratio at the surface is the equilibrium value over ice at the ambient temperature (Pruppacher and Klett, 1997; MacKenzie and Haynes, 1992). If there are uniform ice particles of number $N$ per unit mass of air, the specific humidity will change as follows,

$$
\frac{d q_{v}}{d t}=-N \frac{d m}{d t}=N 4 \pi r D_{v} \rho_{a}\left(q_{s}-q_{v}\right)=\frac{1}{\tau_{q}}\left(q_{s}-q_{v}\right)
$$

where $\rho_{a}$ is the density of air and $q_{s}$ is the mass mixing ratio of water vapour at the particle surface. The quantity $\tau_{q}=\frac{1}{N 4 \pi r D_{v} \rho_{a}}$ is then the relaxation timescale to achieve saturation by depositional growth or evaporation of ice particles. This timescale is inversely proportional to the number density and to the size of the ice particles. Assuming that $\tau_{q}$ and $q_{s}$ are constant in a time step $\Delta t$, by integrating (4), we get

$q_{v}=q_{v 0}-\left(q_{v 0}-q_{s}\right)\left[1-\exp \left(-\frac{\Delta t}{\tau_{q}}\right)\right]$

$q_{i}=q_{i 0}+\left(q_{v 0}-q_{s}\right)\left[1-\exp \left(-\frac{\Delta t}{\tau_{q}}\right)\right]$

for the values of $q_{v}$ and $q_{i}$ at the end of a time step.

\subsection{Nucleation}

Homogeneous nucleation takes place whenever the supersaturation exceeds a critical value $S_{c r}$ (Ren and MacKenzie, 2005),

$S_{c r}=2.349-\frac{T}{259}$,

where $\mathrm{T}$ is in degrees absolute. The number density of newly activated ice particles can be calculated by formulae derived in Ren and MacKenzie (2005). When there are no ice particles or ice nuclei, pure homogeneous nucleation takes place. The concentration of ice particles produced is then

$n_{i}=\frac{\frac{b_{2}}{4 \pi D_{v}}\left(\frac{1}{p} \frac{d p}{d t}-\frac{L_{s}}{R_{v} T^{2}} \frac{d T}{d t}\right) \frac{S_{c r}}{S_{c r}-1}}{\frac{1+\delta}{2}\left(\frac{3 \kappa}{2+\sqrt{1+\frac{9}{\pi} \kappa}}\right)+\frac{1}{1+\delta}\left(\frac{3}{2+\sqrt{1+\frac{9}{\pi} \kappa}}\right)+\delta-1}$,

where the meaning of symbols in Eq. (8) is given in the list of nomenclature in appendix A. Upon nucleation, in the absence of existing ice particles, $N=n_{i}$. When there are ice particles left in the air parcel by previous nucleation events, a secondary homogeneous nucleation case is considered. The concentration of ice particles produced is

$n_{i}^{\prime}=n_{i}-\frac{N b_{2} r}{\frac{1+\delta}{2}\left(\frac{3 \kappa}{2+\sqrt{1+\frac{9}{\pi} \kappa}}\right)+\frac{1}{1+\delta}\left(\frac{3}{2+\sqrt{1+\frac{9}{\pi} \kappa}}\right)+\delta-1}(9)$

$n_{i}^{\prime}$ should be a positive number, otherwise, there is no secondary homogeneous nucleation. Then there are $N=N+n_{i}^{\prime}$ ice particles in the air parcel. New ice particles are allowed to grow and fall for half a time step, then mixed with old ice particles to get a single averaged radius.

No heterogeneous nucleation has been considered in this study because of the uncertainty in how many ice nuclei are present in an air parcel, and the uncertainty in the critical supersaturation for each ice nucleus. If, for future studies, we know the number and the activity spectrum of ice nuclei, they can be easily incorporated into this model by adding the number of heterogeneously activated ice nuclei to $N$ before using Eq. (9).

\subsection{Dehydration}

Ice particles falling out of an air parcel cause the air to dehydrate. Because the size of ice particles is usually in the range from a few micrometers to tens or even hundreds of micrometers, it is necessary to include both the StokesCunningham regime and the Best regime. The changeover between the two regimes is made when the diameter-based Reynolds number, $N_{R e}=10^{-2}$. Thus, the terminal velocity of an ice particle is a function of particle size, $r$, temperature, $T$, and pressure, $p$,

$U=U(r, T, p)$,

where the averaged particle size is calculated by

$r=\left(\frac{3 q_{i}}{4 \pi \rho_{i} N}\right)^{\frac{1}{3}}$.

The detail on how to calculate the terminal velocity can be found in Pruppacher and Klett (1997). As stated above, ice particles are assumed to be spherical in this study. 


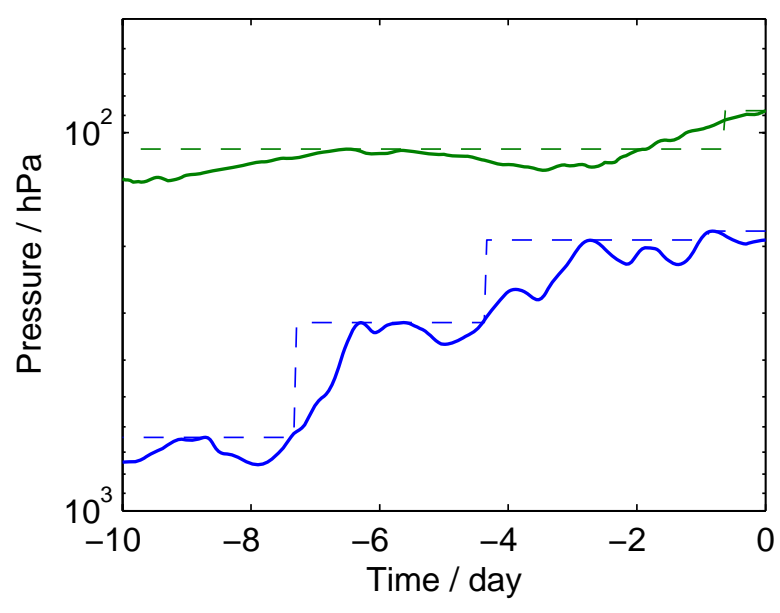

Fig. 1. Two examples of the estimation of cloud-top deduced from the vertical motion of trajectories. See main text for details. Solid lines represent trajectories; dashed lines $r$ epresent their corresponding cloud tops respectively.

Evidently, dehydration in LACM only takes place when a cloud has formed along part of a trajectory. From any incloud trajectory point to the top of the cloud which the trajectory is in, air is assumed to be well mixed. This assumption prevents rapid dilution of the ice particles in an air parcel, which would occur if one assumed a steady sedimentation rate out of a trajectory "box" of some notional height. If the distance from cloud top to the trajectory is $l$, then the fractional change in ice particle number will depend on the particle fall speed and the distance $l$,

$\frac{d N}{N}=-\frac{U d t}{l}$.

Integrating (12) gives

$N=N_{0} \exp \left(-\frac{U}{l} \Delta t\right)=N_{0} \exp \left(-\frac{\Delta t}{\tau_{d}}\right)$,

where $\tau_{d}=\frac{l}{U}$ is the timescale for dehydration. Under our monodisperse assumption, ice content changes similarly by

$q_{i}=q_{i 0} \exp \left(-\frac{\Delta t}{\tau_{d}}\right)$.

To calculate $l$, we need to know the height of the cloud top. In principle, it is impossible to know the cloud-top height from a single trajectory. Rather than introduce another source of information (e.g. from satellite imagery or by modifying the trajectory code to search upwards through the meteorological analyses for cloud-top), or introduce a vertical dimension into the model in the manner of Jensen and Pfister (2004), we deduce the cloud top based on the fact that clouds form when air parcels are ascending, and dissipate when air parcels are descending. With a timestep the same as the temporal resolution of the trajectories, we search each trajectory for cloud events, before running LACM. A cloud event is assumed to begin when the saturation ratio reaches $S_{c r}$. Once a cloud event has begun, instantaneous dehydration is assumed to keep the water vapour mixing ratio at saturation in the air parcel. A cloud event is assumed to finish at a saturation ratio of 0.8. The cloud top is assumed to be the highest point of the portion of a trajectory inside a cloud event. Examples are given in Fig. 1, showing the cloud top for two air-parcel trajectories. They are two of those trajectories used later in the case study (marked by two red stars on the bottom panel of Fig. 6). The lower pair of lines is for a trajectory coming from $750 \mathrm{hPa}$ to $200 \mathrm{hPa}$ in 5 days (roughly from -8 to -3 days). In 10 days, the trajectory has experienced 4 cloud events. The upper pair of lines is for a trajectory staying in the TTL during the 10-day period of the backward trajectory. The trajectory has experienced one cloud event, and is experiencing a second one at the end of the trajectory. From day -2 to -1 , the dashed line is below the solid line. This is because the cloud top is unchanged from the end of the last cloud event to the beginning of the next cloud event. It represents the situation where the air is supersaturated but cloud has not yet formed. To prevent a negative value of $l$ occurring in practice, a minimum value of $200 \mathrm{~m}$ is used.

\subsection{Rehydration}

The water rehydrating an air parcel in the TTL comes either from above by precipitating cirrus clouds, or from below by convective injection. Both mechanisms require information on clouds outside of the air parcel. As a convective cloud can bear more moisture than a cirrus cloud, we try to include the convective injection mechanism first.

To keep our model system simple and consistent, we choose to use ECMWF data as the sole source of information on convection. Fig. 2 shows the water vapour mixing ratios of trajectories interpolated from the ECMWF analysis, into which SSM/I total water vapour of satellite observations has been assimilated (http://www.ecmwf.int/products/data/ operational_system/description/description_2001.html). The trajectories on the map moved from $150 \sim 220 \mathrm{hPa}$ on the left to $130 \mathrm{hPa}$ on the right in 2 days. At the start of this time period, the water vapour mixing ratios were in the range from 5 to $12 \mu \mathrm{mol} / \mathrm{mol}$. $15-22 \mathrm{~h}$ later, abrupt increases to above $25 \mu \mathrm{mol} / \mathrm{mol}$ were found on the trajectories. Satellite images at 06:00 UTC on 7 February 2005 show deep convective systems collocated with these increases in water vapour. To include the effect of deep convection, the water vapour mixing ratio in LACM is reset to the value given by the ECMWF data. The condition for this reset of the water vapour content is that the ECMWF water vapour has an abrupt increase of more than one hundred percent of the value in LACM. In the ECMWF model, as in reality, only deep convection can cause such dramatic increases in water vapour mixing ratios in the TTL. 
The microphysics described above is, of course, only suitable for ice clouds. However, test runs on trajectories that have earlier portions warmer than $-38^{\circ} \mathrm{C}$, initializing trajectories saturated at different temperatures between $0^{\circ} \mathrm{C}$ and $-38^{\circ} \mathrm{C}$, have shown that treating all clouds as ice has negligible influence on the results in the TTL, which are our focus in this study. So we run the microphysical parameterisation along the whole length of all the trajectories, but discard any results for temperatures higher than $-38^{\circ} \mathrm{C}$, because of the very likely involvement of warm cloud processes in the real atmosphere under such conditions.

\subsection{Other methods}

We compare two other trajectory methods with LACM. In the first, labelled "instantaneous dehydration", any water vapour more than saturation with respect to ice is instantaneously removed from the trajectory. As a result, the water vapour mixing ratio along a trajectory is set by the minimum ice saturation ratio the trajectory has experienced. In the second, labelled "interpolated ECMWF", the water vapour mixing ratio along a trajectory is given by interpolating the ECMWF analysis to the position and time of the trajectory. In fact, the water vapour mixing ratio is recorded as a property of trajectories at the time when trajectories are calculated.

\section{Results}

\subsection{Water content following single trajectories}

We first describe the water content changes in single trajectories. Figure 3 shows two of the trajectories on Fig. 2, representing two kinds of trajectory. The blue lines are for a trajectory that went up recently from $500 \mathrm{hPa}$ at -9 days to $130 \mathrm{hPa}$ at -5 days. During this period, the water content decreased by three orders of magnitude. The time lag for dehydration between LACM (blue dashed line) and instantaneous dehydration (blue dotted line) can be up to $8 \mathrm{~h}$. Because of the increase in temperature at -5 days, those ice particles still in the air parcel evaporated, so that more water vapour was kept in the air parcel by LACM than the other two methods. After the ascent to $130 \mathrm{hPa}$, the trajectory stayed above $200 \mathrm{hPa}$, and its water content was kept constant by LACM in the following three and a half days. In contrast, the value interpolated from ECMWF fluctuated somewhat. An abrupt increase taking place between day -2 and -1 was the result of convective injection from below, which has been shown in Fig. 2. This is not included in the minimum-saturationratio calculation, and also disappears much more rapidly in the interpolated-ECMWF calculation than in the LACM calculation. Camparison with satellite images (see Fig. 4 and Sect. 3.1.1 for details), suggests that the relatively slow decay of this injected water in the LACM calculation, leading to extended cloudiness, is the most realistic of the three calculations.

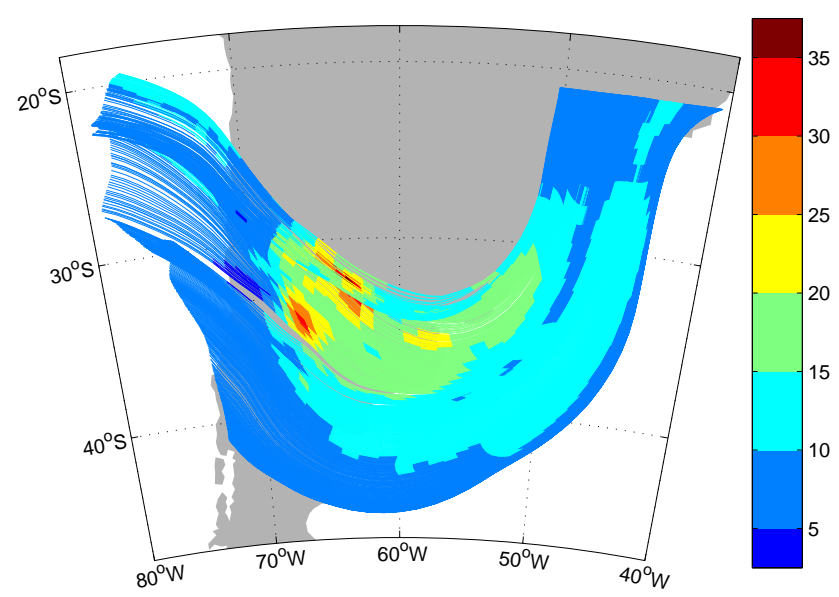

Fig. 2. Water vapour mixing ratios $(\mu \mathrm{mol} / \mathrm{mol})$ interpolated from the ECMWF analysis onto 2-day backward trajectories released from the $130 \mathrm{hPa}$ horizontal flight leg flown by the high-altitude aircraft Geophysica on 8 February 2005 in Brazil for the TROCCINOX field campaign. Flow along trajectories is from left to right of the figure. The underlying map shows land in grey.

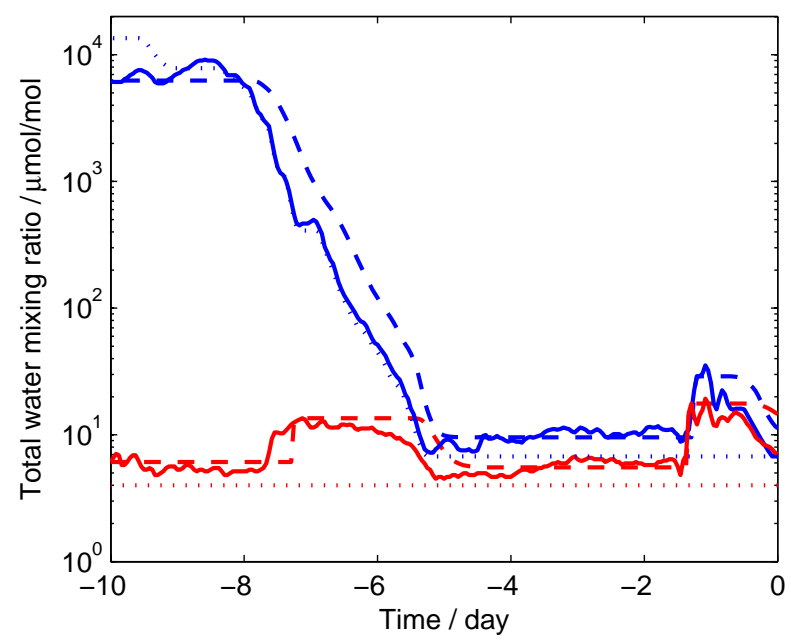

Fig. 3. Water vapour mixing ratio $(\mu \mathrm{mol} / \mathrm{mol})$ along 10 -day backward single trajectories. Blue lines are for a trajectory that entered the TTL on day -5 ; red lines are for a trajectory that was always in the TTL. Solid lines are interpolated from ECMWF analyses, dashed lines show the LACM results, and dotted lines show the minimum ice saturation ratio along the trajectory.

The red lines in Fig. 3 are for a trajectory that had been above $200 \mathrm{hPa}$ for all of the 10-day period. Two convective injections of water vapour were experienced by the trajectory, one between day -8 and -7 , another between day -2 and -1 . The effects of the first injection lasted about 2 days. The implication is that without convective injection of water vapour, Lagrangian models of the TTL will have a dry bias. 


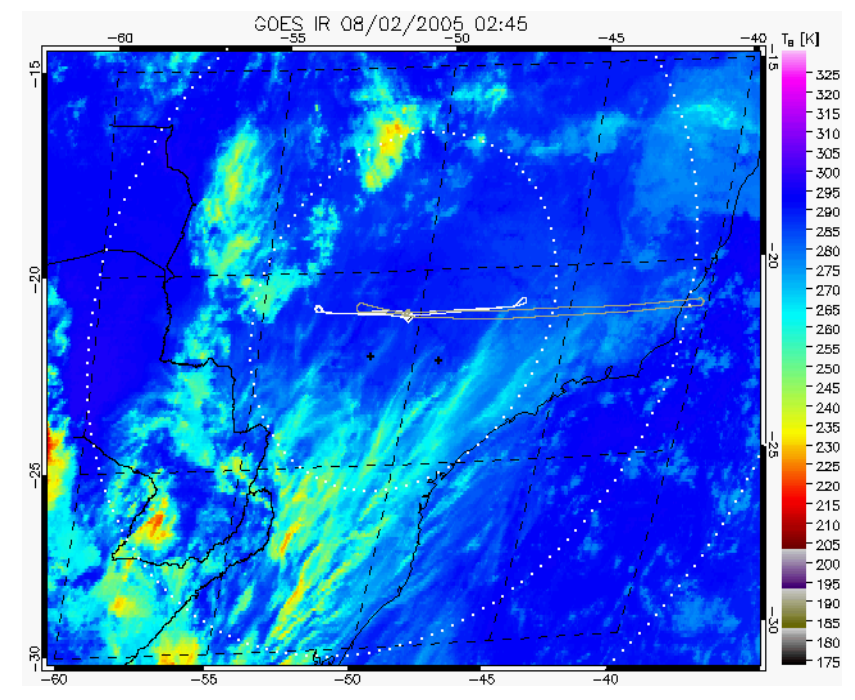

Fig. 4. GOES infrared image for the TROCCINOX region, at 02:45 UTC on 8 February 2005, displayed as equivalent blackbody temperature (K). Red and yellow colours indicate high, dense, cloud tops. Cyan colours indicate lower cloud or less i.r.-opaque high cloud. Fight tracks of the Geophysica (grey line) and Falcon (white line) are superimposed. (courtesy of Dominik Brunner, ETH Zurich).

Initial conditions also affect trajectory behaviour. In LACM, we set initial conditions, tropospheric and stratospheric, according to ECMWF analysis. In finding the minimum saturation mixing ratio a trajectory has experienced, however, we set initial conditions to be either saturated with respect to ice, or at water mixing walue of $4 \mu \mathrm{mol} / \mathrm{mol}$ if the trajectory started from the stratosphere 10 days before. It is necessary to avoid or prevent unrealistically high values of minimum saturation mixing ratio for those trajectories that started from the stratosphere. Some studies on entry level of stratospheric water vapour ((Bonazzola and Haynes, 2004; Fueglistaler et al., 2004)) excluded from trajectory assembles those trajectories that did not pass through the TTL during the whole trajectory length. We do not omit any trajectories, because all the trajectories are needed for the comparison with aircraft observations below. Gettelman et al. (2002) used a water vapour mixing ratio of $4 \mu \mathrm{mol} / \mathrm{mol}$ for trajectories started from the stratosphere. ECMWF analysis can also be used as initial conditions for the instantaneous dehydration method, but we adopt the method of Gettelman et al. (2002) to prevent misrepresenting initial conditions as the minimum saturation mixing ratios. As a result, the red dotted line (from the instantaneous dehydration method) in Fig. 3 is at constant value of $4 \mu \mathrm{mol} / \mathrm{mol}$. This is because the trajectory started from the stratosphere 10 days before and had been set to that value initially, experiencing temperatures of saturation mixing ratios higher than $4 \mu \mathrm{mol} / \mathrm{mol}$.

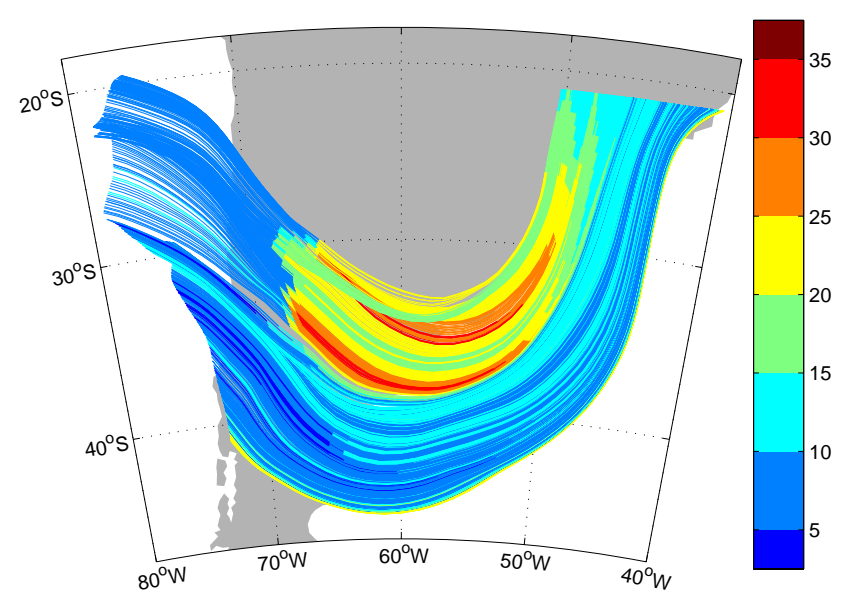

Fig. 5. Total water mixing ratio $(\mu \mathrm{mol} / \mathrm{mol})$ by LACM for the last 2 days of 10-day backward trajectories released from the $130 \mathrm{hPa}$ horizontal flight leg flown by the high-altitude aircraft Geophysica on 8 February 2005 in Brazil for the TROCCINOX field campaign. Flow along trajectories is from left to right of the figure. The underlying map shows land in grey.

\subsubsection{Anvil outflow}

In Fig. 2, convective injection moistened some trajectories so that they showed mixing ratios of up to $30 \mu \mathrm{mol} / \mathrm{mol}$, but all these high values decreased to below $20 \mu \mathrm{mol} / \mathrm{mol}$ within $6 \mathrm{~h}$. In other words, the water vapour mixing ratio returned to a larger-scale average value in the next output step because of numerical diffusion in ECMWF. However, water vapour and total water are not usually distributed smoothly in space, and anvils from convection can last much longer than six hours. Figure 4 shows an infrared satellite image obtained by GOES at 02:45 UTC on 8 February 2005. From $\left(53^{\circ} \mathrm{W}, 30^{\circ} \mathrm{S}\right)$ to $\left(47^{\circ} \mathrm{W}, 21^{\circ} \mathrm{S}\right)$, the anvil-generated cloud formed a continuous cloud patch more than $1000 \mathrm{~km}$ long. We estimate that it took about $12 \mathrm{~h}$ to form a cloud patch of this length. From the satellite image sequence (not shown), it is apparent that the cloud patch was generated by convection which died out overnight. Figure 5 shows the total water mixing ratio from LACM. In contrast to the ECMWF analysis, shown in Fig. 2, here air parcels moistened by convection maintain high total water mixing ratios much longer, which shows as stripes along their path in Fig. 5. Although the satellite image in Fig. 4 is only a snapshot, the stripy cirrus-cloud features present are similar to the patterns formed by the trajectories over time. In making this comparison, we implicitly assume that the wind field was approximately stationary over the twelve hours prior to the satellite image but, even if the comparison between satellite image and trajectory calculation is not perfect, it does indicate that the trajectories are capturing atmospheric behaviour that the ECMWF analysis is missing. 


\subsection{Comparison with aircraft observations}

The second TROCCINOX field campaign was carried out in Brazil during February 2005 (Schumann et al., 2007¹). The high-altitude aircraft Geophysica attended the campaign and made eight local fights based at Araçatuba, Sao Paolo State, Brazil ( $\left.21^{\circ} 8^{\prime} 35^{\prime \prime} \mathrm{S}, 50^{\circ} 25^{\prime} 39^{\prime \prime} \mathrm{W}\right)$. Along with many other instruments, the Geophysica carried FISH - The Fast In-situ Stratospheric Hygrometer - developed at the Forschungszentrum Jülich (Germany). FISH is based on the Lyman $-\alpha$ photofragment fluorescence technique (Zöger et al., 1999). The overall accuracy of this hygrometer is $6 \%$, or $0.3 \mu \mathrm{mol} / \mathrm{mol}$ in the case of the very low mixing ratios that occur in the tropics. In the presence of clouds, FISH measures total water, with an over-sampling of cloud elements (Schiller et al., 1999). For typical Geophysica cruising altitude and speed, the over-sampling factor for particles with radii larger than $4 \mu \mathrm{m}$ is 5 . Thus FISH measurements are very sensitive to cloud water content and have been used previously to study the variability of cloud and water vapour in the TTL (MacKenzie et al., 2006). FISH was on board for all the eight local flights, measuring total water mixing ratio (water vapour and ice). For flight tracks of the eight flights at pressure below $250 \mathrm{hPa}, 10$-day backward trajectories were calculated every $10 \mathrm{~s}$ using FLEXTRA (Stohl, 1999). The FISH measurements were then simulated by three methods: parameterised microphysics along trajectories (i.e., LACM), minimum saturation mixing ratio calculated along trajectories (i.e., "instantaneous dehydration"), and direct interpolation from the ECMWF analysis onto the trajectories.

\subsubsection{Case study}

Examples are shown in Fig. 6 for the flights of 5, 8, 18 February 2005. The figure shows LACM reconstructions and interpolated-ECMWF reconstructions as well as the FISH observations themselves. A so-called "golden day" of thunderstorm chasing occurred on the 4 February 2005. On this day the Geophysica carried out manoeuvres very close to an active, isolated, tropical thunderstorm. This day is not chosen for a case study, since we would not expect such subgrid convection to be reproduced accurately by the ECMWF analysis. The 5 February is chosen for a case study, because the model-measurement comparison on this day is the worst for all except the "golden day". The reason for the poor model-data intercomparison is given in Sect. 3.2.4, below. On both the 8 and 18 February, the figure shows that, on most parts of the flights, the LACM reconstruction is in better agreement with the observation than is the ECMWF analysis. Considering that we use the ECMWF analysis as our sole source of information, any improvement from the ECMWF result comes from the inclusion of more relevant processes in LACM. The three processes considered in LACM are that

\footnotetext{
${ }^{1}$ Schumann, U., et al.: The TROCCINOX campaigns, in preparation, 2007
}

Table 1. Correlation coefficients between FISH observation and model results for all portions of the eight TROCCINOX flight tracks at pressures below $250 \mathrm{hPa}$. The highest correlation coefficient for each flight is shown in bold face type.

\begin{tabular}{llll}
\hline Flight date & LACM & ECMWF & $S R_{\min }$ \\
\hline 2005.2 .01 & 0.923 & $\mathbf{0 . 9 4 8}$ & 0.779 \\
2005.2 .04 & 0.458 & $\mathbf{0 . 5 0 2}$ & 0.462 \\
2005.2 .05 & $\mathbf{0 . 8 7 4}$ & $\mathbf{0 . 8 7 4}$ & 0.829 \\
2005.2 .08 & $\mathbf{0 . 9 6 1}$ & 0.942 & 0.762 \\
2005.2 .12 & 0.819 & $\mathbf{0 . 9 3 7}$ & 0.816 \\
2005.2 .15 & 0.962 & $\mathbf{0 . 9 8 2}$ & 0.907 \\
2005.2 .17 & 0.894 & $\mathbf{0 . 9 1 0}$ & 0.875 \\
2005.2 .18 & 0.868 & $\mathbf{0 . 9 0 7}$ & 0.844 \\
\hline
\end{tabular}

(1) total water mixing ratio is conserved - outside of clouds - in an air parcel whose position is described by a trajectory; (2) dehydration is via the sedimentation of ice particles in clouds that the trajectory rises through; and (3) rehydration is by convection that is itself deduced from abrupt increases of water vapour in the ECMWF analysis. Because we do not consider any exchange between neighbouring air parcels, LACM allows more variability in its reconstruction of total water along a flight track, whereas diffusion in the ECMWF analysis makes that reconstruction of total water too smooth. Overall, however, it should be noted that both reconstructions are in good agreement with the observations.

\subsubsection{Statistical indicators}

Table 1 shows the correlation coefficients of the results achieved by LACM, ECMWF analysis, or the minimum saturation ratio, $S R_{\min }$, reconstructions against the FISH observation, for all portions of the eight local flight tracks at pressure below $250 \mathrm{hPa}$. Note that $S R_{\min }$ is $4 \mu \mathrm{mol} / \mathrm{mol}$ in situations explained in Sect. 3.1. Except on the 4 February, all coefficients are higher than 0.76. That is, all the reconstruction techniques capture more than three quarters of the standard deviation in the observations; the ECMWF analysis reconstruction achieves the highest correlation coefficients in all but one case, that of 8 February, for which the LACM reconstruction has the highest correlation coefficient. However, the correlation coefficient over the whole portion of the flight at pressure below $250 \mathrm{hPa}$ is not the best indicator of which reconstruction is better around the cold-point tropopause, because the correlation coefficient is heavily influenced by the rapid decrease in water with height that is captured by all three reconstruction methods. For example, the correlation coefficient for the ECMWF analysis reconstruction is higher than that for the LACM reconstruction on the 18 February, but the bottom panel of Fig. 6 shows that LACM performs better close to the cold point (i.e., 18.7521.0 h (18:45-21:00 UTC)). 
Table 2. Deviation of normalized $\ln \left(q_{t}\right)$ of model results from observations. The lowest deviation for each flight is shown in bold face type.

\begin{tabular}{lllll}
\hline Flight date & LACM & ECMWF & $S R_{\min }$ & $\overline{L A C M}$ \\
\hline 2005.2 .01 & 0.161 & $\mathbf{0 . 1 3 1}$ & 0.215 & 0.155 \\
2005.2 .04 & 0.339 & $\mathbf{0 . 2 6 6}$ & 0.352 & 0.315 \\
2005.2 .05 & 0.406 & $\mathbf{0 . 2 9 5}$ & 0.276 & 0.390 \\
2005.2 .08 & 0.140 & 0.146 & 0.302 & $\mathbf{0 . 1 2 5}$ \\
2005.2 .12 & 0.275 & $\mathbf{0 . 1 6 5}$ & 0.416 & 0.246 \\
2005.2 .15 & 0.154 & 0.152 & 0.304 & $\mathbf{0 . 1 3 0}$ \\
2005.2 .17 & 0.230 & 0.195 & 0.374 & $\mathbf{0 . 1 9 4}$ \\
2005.2 .18 & 0.303 & 0.330 & 0.410 & $\mathbf{0 . 2 7 3}$ \\
\hline
\end{tabular}

* Deviation was calculated in analogy to variance, but with the sample mean replaced by the FISH measurement corresponding to the model result.

As an alternative to using a simple linear correlation, we investigated the spread of the model results from the observations by calculating the deviation of each model from the corresponding FISH observation, where deviation is defined by analogy to variance. To give extra weight to the smaller values of total water in the three-orders-of-magnitude range, $\ln \left(q_{t}\right)$ is used and normalized by the FISH measurement at the point. Hence, the deviation is calculated as

$D e v=\sqrt{\frac{\sum_{j=1}^{n}\left[\frac{\ln \left(q_{t m j}\right)-\ln \left(q_{t o j}\right)}{\ln \left(q_{t o j}\right)}\right.}{n-1},}$

where $j$ indexes the point where a FISH measurement and model calculations are made. Subscript $o$ indicates observations, and subscript $m$ indicates any one of the methods used to reconstruct the total water mixing ratios.

This indicator emphasises smaller values of $q_{t}$ and,hence, is useful in measuring which method is better for estimating the entry-level of stratospheric water vapour. The smaller the deviation, the closer the model is to the observations. According to this indicator, LACM is closer to the observations than the ECMWF analysis for the flights on the $8^{\text {th }}$ and $18^{\text {th }}$ of February.

However, the fact that LACM allows more variability along a flight track means that LACM deviation scores can be relatively high even when the model results are in overall good agreement with observations. That is, a bigger random error in LACM overshadows its improved systematic error, compared to the interpolated-ECMWF reconstruction, because the deviation statistic does not distinguish between these two sources of error. To illustrate this, a sliding mean of 29 points (corresponding to about $50 \mathrm{~km}$ ) is applied to LACM results along the flight track. The results are also listed in Table 2 in the column headed $\overline{L A C M}$. The deviation values in this column are still smaller than those in the ECMWF column for the 8 and 18 February, but are now also
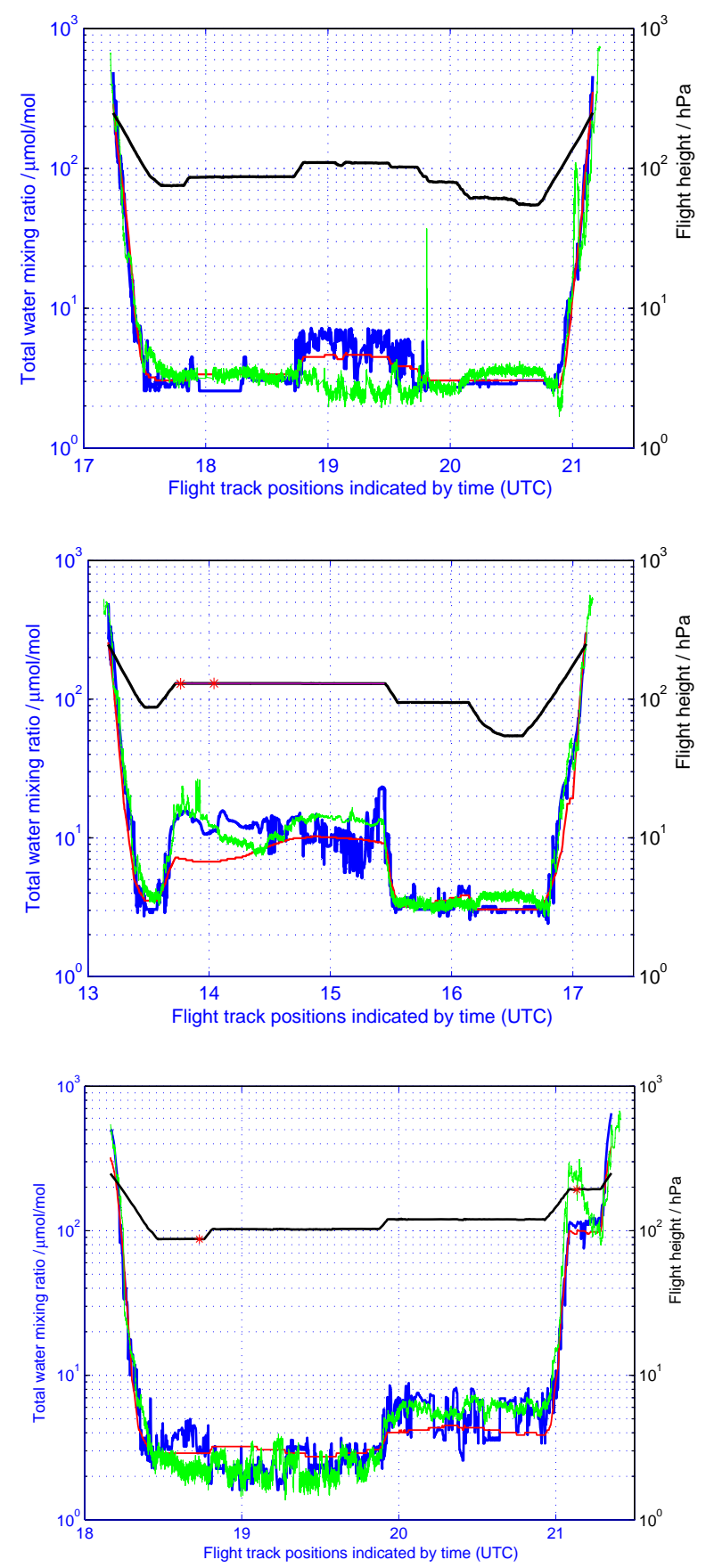

Fig. 6. Water vapour mixing ratios $(\mu \mathrm{mol} / \mathrm{mol})$ by FISH measurements (green), ECMWF-analysis reconstructions (red), and LACM reconstructions (blue), using 10-day backward trajectories released from the flight tracks flown by the high-altitude aircraft Geophysica on the 5, 8, 18 February 2005 (from top to bottom), for the TROCCINOX field campaign in Brazil. The flight heights are also shown in black. In the middle panel, the magenta line shows where the trajectories in Figs. 2 and 5 ended, while the two red stars correspond to Fig. 3. In the bottom panel, the two red stars correspond to Fig. 1. 


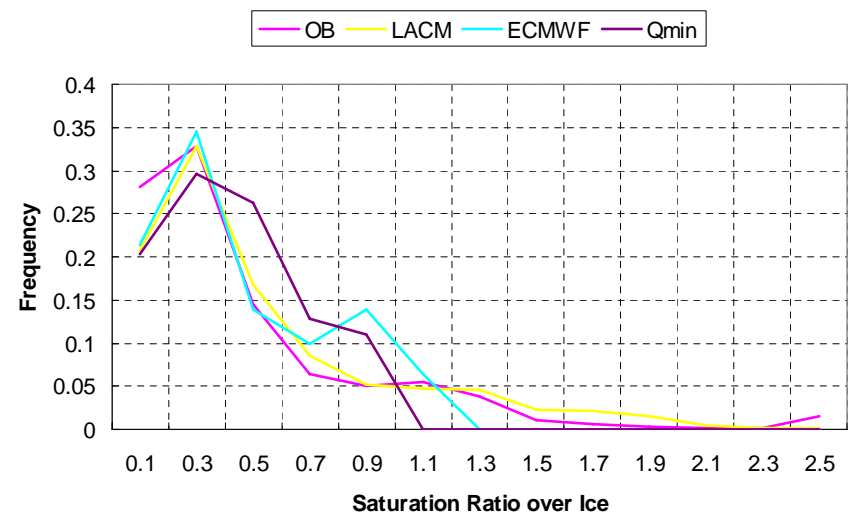

Fig. 7. The frequencies of "maximum potential relative humidity over ice", $\mathrm{RH}_{i, \max }$, values in the observations (lilac) and in the LACM reconstruction (yellow). See main text for a definition of $\mathrm{RH}_{i, \max }$. Also shown are conventional relative humidities for the instantaneous dehydration reconstruction (dark purple), and direct interpolation from the ECMWF analysis onto the trajectories (cyan). The histograms are constructed with a relative humidity bin-width of 0.2 , and are scaled so that the total frequency for any data set is equal to one.

smaller for the 15 and 17 February. Using a sliding mean on the ECMWF results has little effect, as the results are already very smooth.

To complement the point-by-point comparisons described above and in Tables 1 and 2, Fig. 7 shows the histograms of 'maximum potential relative humidities over ice', $\mathrm{RH}_{i, \max }=q_{t} / q_{s}$, in the observations and LACM. "Maximum potential relative humidity" is equal to the conventional relative humidity, $\mathrm{RH}_{i}=q_{v} / q_{s}$, in cloud-free air, and is $q_{i} / q_{s}$ larger than the relative humidity when clouds are present. Figure 7 also shows the conventional relative humidity from the ECMWF and the instantaneous dehydration reconstructions. It is clear from Fig. 7 that most observations are for dry air $\left(\mathrm{RH}_{i, \max }<0.5\right)$, and that the ECMWF and LACM reconstructions capture this mode reasonably well, albeit with a bias towards slightly higher $\mathrm{RH}_{i}$. The instantaneous dehydration reconstruction is significantly broader at low $\mathrm{RH}_{i}$ than the observations or the other reconstructions. The observations also show a long tail of high $\mathrm{RH}_{i, \max }$, to values well above $100 \%$. This tail is captured well by LACM (the comparison with the ECMWF and the instantaneous dehydration reconstructions is not relevant in this part of the figure, where $\left.\mathrm{RH}_{i, \max } \neq \mathrm{RH}_{i}\right)$. The observations and LACM show a secondary mode in the frequency distribution at $\mathrm{RH}_{i, \max } \approx 1.1$; the ECMWF and instantaneous dehydration reconstructions have a much more marked mode at $\mathrm{RH}_{i, \max } \approx 0.9$.
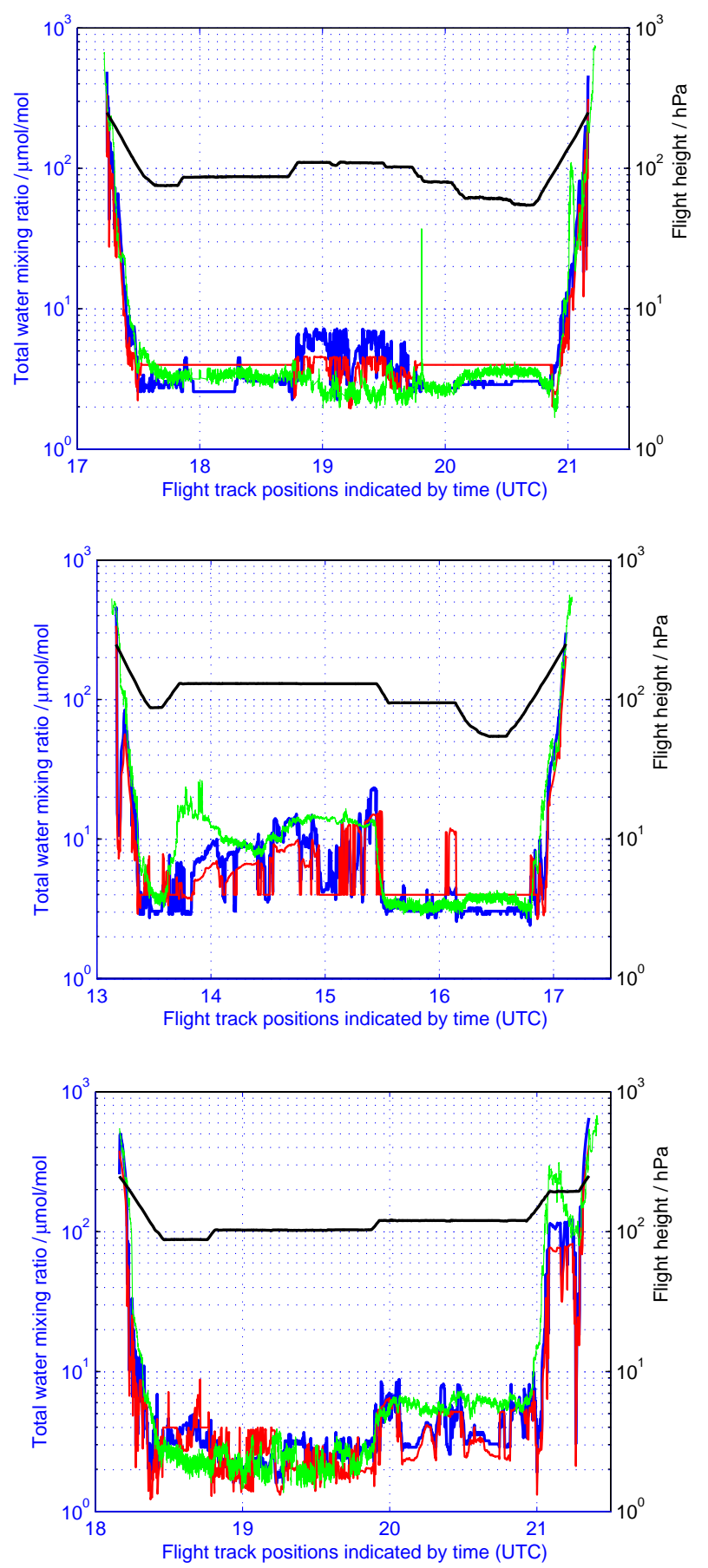

Fig. 8. Water vapour mixing ratios $(\mu \mathrm{mol} / \mathrm{mol})$ by FISH measurements (green), instantaneous dehydration reconstructions (red) and LACM reconstructions without rehydration (blue), using 10day backward trajectories released from the flight tracks flown by the high-altitude aircraft Geophysica on the 5, 8, 18 February 2005 (from top to bottom), for the TROCCINOX field campaign in Brazil. The flight heights are also shown in black, c.f., Fig. 6 


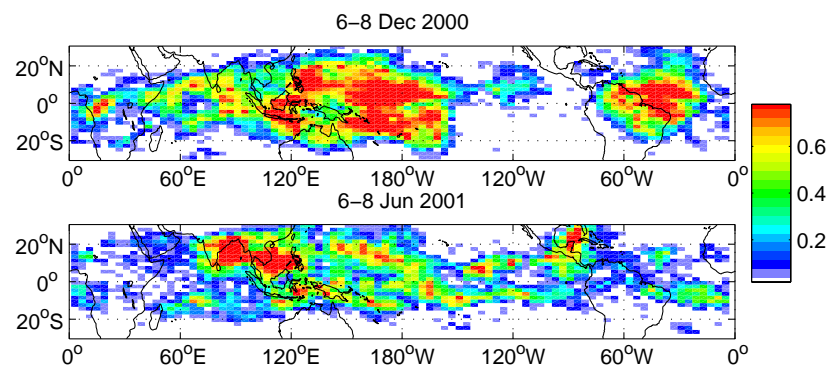

Fig. 9. The frequency of optically thin clouds in the TTL for threeday snapshots in northern hemisphere summer and winter. For each case, 12 sets of domain-filling backward trajectories, upon which LACM was applied, were generated at 6-h intervals. The frequency at a point was calculated by counting how many times, out of the 12 snapshots, there was ice water at the trajectory end-point. The red and yellow in the figure represent the regions where cirrus clouds are most likely to appear, while the white means no appearance of clouds on any of the three levels of 360,370 , and 380 Kelvin potential temperatures. Note, the blank areas in Fig. 10 mean that no reliable data are available.

\subsubsection{Sensitivity tests}

Sensitivity tests have been done to quantify the contribution to the reconstructions arising from different processes. One test, which we have already been discussing in passing, applies instantaneous dehydration to the trajectories. A second test uses LACM, but without the rehydration parameterisation, to see if it is necessary to include this process.

Figure 8 shows examples of these sensitivity tests, for the 5, 8, 18 February 2005. There are horizontal parts of red lines (i.e., for the instantaneous dehydration reconstruction) with values of $4 \mu \mathrm{mol} / \mathrm{mol}$ on the 5th and 8th cases, which results from initialising trajectories in the stratosphere. Corresponding to the horizontal parts of red lines, the values of blue lines (LACM without rehydration) are also set by initial conditions, at least when a value is less than $4 \mu \mathrm{mol} / \mathrm{mol}$, which is set by the ECMWF analysis. For these parts of flight tracks, dehydration cannot make them become drier than $4 \mu \mathrm{mol} / \mathrm{mol}$. For far fewer occasions, unsaturated initial conditions cause LACM without rehydration to be drier than the instantaneous dehydration reconstruction - for example, at 20:20 UTC on the 18 February.

Apart from the above differences caused by initialisation, the fact that microphysical processes take time to complete means more water will be kept in an air parcel when a microphysical parameterisation is used. Such an effect is shown by the fact that blue values are usually higher than red values on Fig. 8. However, without rehydration, both blue and red lines have many downward spikes deviating from the FISH observation (green lines). The interpolated-ECMWF reconstruction does not suffer from this dry bias (see Fig. 6), because convection in the ECMWF model moistens air parcels dramatically, by pumping moist air upwards. It can be seen, by comparing Fig. 8 with Fig. 6 , that it is necessary to include rehydration, even though trajectories are only 10 days long.

Instantaneous dehydration has been used in many Lagrangian assessments of the entry-level of stratospheric water vapour, e.g. Bonazzola and Haynes (2004); Fueglistaler et al. (2004, 2005). The correlation coefficient and deviation indicator from instantaneous dehydration runs are shown in Tables 1 and 2 under the heading $S R_{\min }$. According to these statistical indicators, LACM always improves on the instantaneous dehydration approach, and usually by a large amount.

\subsubsection{Uncertainty}

Although the Lagrangian method can provide an improvement to the large-scale data used to generate trajectories, it is still subject to the quality of that large-scale data. A good agreement with observations can only be achieved when the temperature history of trajectories is correct. However, the sub-grid variability of temperature has not been included in this study. This could be the reason why LACM failed to reproduce the lower water vapour mixing ratios measured by FISH between 18:40 and 19:40 UTC on the 5 February (see the top panel of Fig. 6). Backward trajectories released from that part of the flight track indicate that the air sampled came from a region where there was deep convection the previous day. The minimum water content measured on the previous day (4 February) was $3 \mu \mathrm{mol} / \mathrm{mol}$, clearly higher than the values here. It is possible that the air here dehydrated through a mechanism suggested by Danielsen (1982). Because there have been ice particles in the upwind convective anvil, homogeneous nucleation is no longer necessary for dehydration to take place, i.e., LACM is not well configured for the Danielsen dehydration regime. However, for this specific case, the model is still too wet even if instantaneous dehydration is assumed (cf. the top panel of Fig. 8), which means that ultimately it is the temperature history - rather than the microphysics - that has not been described correctly.

\subsection{Cirrus occurrence frequency in the TTL}

One significant advantage of LACM over the instantaneous dehydration scheme is that LACM provides information on cirrus clouds. Cirrus clouds in the TTL are important because of their effects in radiation and their role in heterogeneous chemistry, as well as a "cold trap" for tropospheric water.

Using LACM, the cirrus cloud occurrence frequency in the TTL was simulated for a boreal winter case (6-8 December 2000) and a boreal summer case (6-8 June 2001) (see Fig. 9). These two periods were chosen because there were MODIS satellite retrievals (Dessler and Sherwood, 2003, see Fig. 10 as a reproduction of their Fig. 2) for comparison. For each case, 12 sets of domain-filling 10-day backward trajectories 


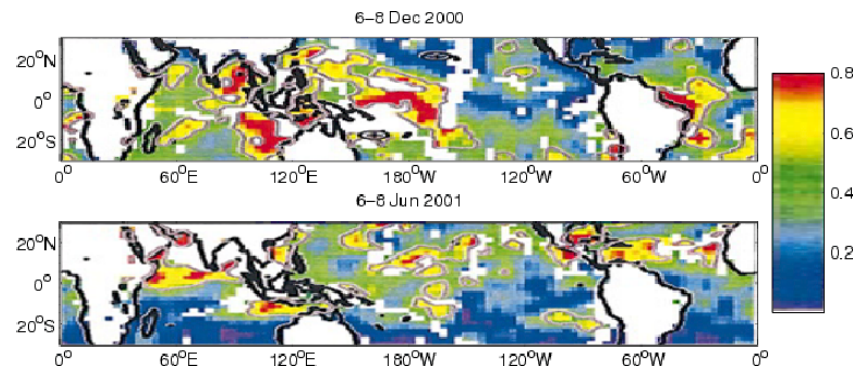

Fig. 10. Fraction of observations (colour scale) between latitude $30^{\circ} \mathrm{N}$ and $30^{\circ} \mathrm{S}$ and longitude 0 to $360^{\circ} \mathrm{E}$ during the 6-8 December 200 (upper panel) and 6-8 June 2001 (lower panel) periods whose optical depth $\tau$ exceeded 0.02. White indicates less than 1000 measurements in the box. Gray contours indicate the $30 \%$ frequency contour for $\tau>0.03$. (Reproduction of Fig. 2 of Dessler and Sherwood, 2003, by the courtesy of the authors and AMS)

were generated every $6 \mathrm{~h}$. Each set was composed of trajectories at $2^{\circ}$ of longitude by $1^{\circ}$ of latitude grid on 360, 370, and 380 Kelvin potential temperature levels. Then LACM was applied to each set of trajectories to get a snapshot of ice water content in the TTL at the end of each set of trajectories. The frequency at a grid point was calculated by counting in how many of the 12 snapshots there was ice water. The resolution has been reduced to $4^{\circ} \times 2^{\circ}$ to smooth off smaller features on Fig. 9.

For the winter case, cirrus clouds concentrate over the tropical Western Pacific Ocean and maritime continent, and the tropical Western Atlantic and northern Brazil. For the summer case, the spatial distribution of cirrus clouds is less concentrated. Model results show a maximum in occurrence in the Bay of Bengal and in the southern Asian monsoon region, but MODIS retrieval is not available over lands for comparison. Off the west coast of North Africa in June, the model doesn't produce as high a frequency as shown on the lower panel of Fig. 10, which Dessler and Sherwood (2003) suspected was due to dust.

In Sect. 3.2.3, it has been established that convective injection is a source of water vapour in the TTL. The contribution of this source to global cirrus cloud occurrence is investigated here by running LACM with or without rehydration for the MODIS case studies. Figure 11 shows the increase of cloud occurrence frequency by including convective injection of water vapour. The increase in cloud frequency occurs where LACM without rehydration (figure not shown) underestimates the occurrence, usually around the most convective regions. In general, however, convective injection is a secondary source of water vapour in the TTL compared to along-trajectory transport.

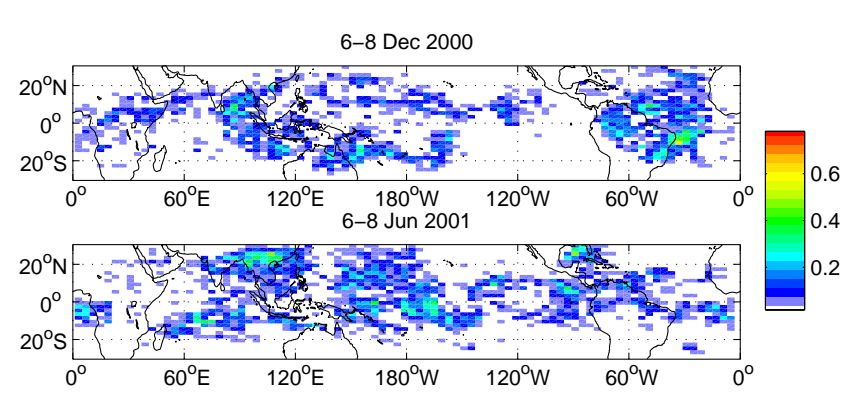

Fig. 11. Difference plot, showing the frequencies given in Fig. 9 minus those of an equivalent run, but with no injection of water vapour by convection. Coloured areas in the figure show, therefore, where cirrus-cloud occurrence frequency increases in LACM when water-vapour injection by convection is included.

\section{Conclusions}

In this paper, a Lagrangian air-parcel cirrus model (LACM) is developed to diagnose the processes controlling total water in the TTL. LACM applies parameterised microphysics to air parcel trajectories, including the homogeneous freezing of aerosol droplets, growth/sublimation and the sedimentation of ice particles. Rehydration of air parcels is also considered by resetting water vapour mixing ratios to the value at the point in the 4-D data used to generate the trajectories, when certain conditions are satisfied. These conditions are imposed to restrict the processes contributing to rehydration. The most likely physical mechanism for this rehydration is the injection of moist convected air into the TTL by deep convection.

The mixing ratios of total water in the TTL, measured by a high-altitude aircraft over Brazil (during the TROCCINOX campaign), have been reconstructed by LACM using trajectories generated from the ECMWF analysis. The reconstructed total water mixing ratios along aircraft flight tracks are compared with observations. Process-oriented analysis shows that modelled cirrus cloud events are responsible for dehydrating the air parcels coming from lower levels down to $2 \mu \mathrm{mol} / \mathrm{mol}$. Without adding water back to the trajectories, the LACM-without-rehydration reconstruction shows a dry bias. Occasionally re-setting the total water in LACM using the ECMWF analysed specific humidity in regions where the model predicts convection, removes the dry bias. This indicates that the ECMWF model captures the gross feature of the rehydration of air in the TTL by convection. By picking up the main contributing processes to dehydration and rehydration in the TTL, LACM reconstructs total water mixing ratios along aircraft flight tracks in better agreement with observations than the ECMWF analysis themselves, particularly with respect to the occurrence of high relative humidities (Fig. 7) and the longevity of cirrus clouds in the TTL (Fig. 5). 
The methodology in this paper is to apply a selfconsistent analytical parameterisation of cirrus cloud (Ren and MacKenzie, 2005) to three-dimensional trajectories to mimic the dehydration of air parcels passing through the tropical tropopause layer. The parameterisation is physically sound and computationally efficient, which makes LACM suitable for a number of different tasks: analysing observations, as in the present paper, providing cirrus forecasts for scientific campaigns, and assessing the entry-level of stratospheric water vapour through model studies.

When domain-filling backward trajectories from operational forecast data are used, LACM can forecast cirrus clouds and water vapour in the TTL. This has been done to provide information for flight planning during the TROCCINOX and SCOUT-O3 field campaigns in 2005 and will be reported in a forthcoming paper.

\section{Appendix A}

\section{Notation}

\begin{tabular}{|c|c|}
\hline$b_{2}$ & $=\frac{\alpha}{D_{v}} \sqrt{\frac{R_{v} T}{2 \pi}}$ \\
\hline$D$ & Dehydration rate \\
\hline$D_{v}$ & Diffusivity of water molecules in air \\
\hline$\delta$ & $=b_{2} r_{0}$, dimensionless aerosol radius \\
\hline$\Delta t$ & Time step \\
\hline$\kappa$ & $=\frac{2 b_{1} b_{2} \tau}{(1+\delta)^{2}}$ dimensionless freezing timescale \\
\hline$l$ & Distance from cloud-top to the trajectory \\
\hline$L_{S}$ & latent heat of water sublimation \\
\hline$m$ & Ice particle mass \\
\hline$n_{i}$ & $\begin{array}{l}\text { Number density of ice particles generated } \\
\text { by pure homogeneous nucleation }\end{array}$ \\
\hline$n_{i}{ }^{\prime}$ & $\begin{array}{l}\text { Number density of additional ice particles } \\
\text { generated by secondary homogeneous nucleation }\end{array}$ \\
\hline$N$ & Total number density of ice particles \\
\hline$p$ & Air pressure \\
\hline$q_{i}$ & Equivalent ice content mixing ratio \\
\hline$q_{s}$ & $\begin{array}{l}\text { Mass mixing ratio of water vapour at the particle } \\
\text { surface }\end{array}$ \\
\hline$q_{t}$ & Total water mixing ratio \\
\hline$q v$ & Water vapour mixing ratio \\
\hline$r$ & Ice particle radius \\
\hline$R$ & Rehydration rate \\
\hline$R_{v}$ & Gas constant of water vapour \\
\hline $\mathrm{RH}_{i}$ & Relative humidity of water vapour over ice, $q_{v} / q_{s}$ \\
\hline $\mathrm{RH}_{i, \max }$ & $\begin{array}{l}\text { Maximum potential relative humidity of water } \\
\text { vapour over ice, } q_{t} / q_{s}\end{array}$ \\
\hline$\rho_{a}$ & Density of air \\
\hline$\rho_{i}$ & Density of ice \\
\hline$\rho_{v}$ & Mass concentration of water in the vapour phase \\
\hline$\rho_{s}$ & $\begin{array}{l}\text { Mass concentration of water at the particle } \\
\text { surface }\end{array}$ \\
\hline
\end{tabular}
$S_{c r} \quad$ saturation ratio above which significant homogeneous freezing takes place
$T$ Temperature
$\tau_{d} \quad$ Timescale for dehydration
$\tau_{q} \quad$ Relaxation timescale towards saturation equilibrium
$U \quad$ Terminal velocity of ice particles

Acknowledgements. This research was funded by the Natural Environment Research Council (CWVC NER/T/S/2000/00977) and the European Commission (TROCCINOX project EVK2CT-2001-00122, SCOUT-O3 project GOCE-CT-2004-505390). Special thanks are due to the field campaign teams who make the precious measurements. Thanks also goes to the British Atmospheric Data Centre, which provided ECMWF data, and to A. Stohl (NILU) who developed the free FLEXTRA trajectory software.

Edited by: H. Schlager

\section{References}

Bonazzola, M. and Haynes, P. H.: A trajectory-based study of the tropical tropopause region, J. Geophys. Res.-Atmos., 109, D20112, doi:10.1029/2003JD004356, 2004.

Brewer, A. W.: Evidence for a world circulation provided by the measurements of helium and water vapour distribution in the stratosphere, Q. J. Roy. Meteor. Soc., 75, 351-363, 1949.

Danielsen, E. F.: A dehydration mechanism for the stratosphere, Geophys. Res. Lett., 9, 605-608, 1982.

Dessler, A. E.: A reexamination of the "stratospheric fountain" hypothesis, Geophys. Res. Lett., 25, 4165-4168, 1998.

Dessler, A. E. and Sherwood, S. C.: A model of HDO in the tropical tropopause layer, Atmos. Chem. Phys., 3, 2173-2181, 2003, http://www.atmos-chem-phys.net/3/2173/2003/.

Fueglistaler, S., Wernli, H., and Peter, T.: Tropical troposphereto-stratosphere transport inferred from trajectory calculations, J. Geophys. Res.-Atmos., 109, 2004.

Fueglistaler, S., Bonazzola, M., Haynes, P. H., and Peter, T.: Stratospheric water vapor predicted from the Lagrangian temperature history of air entering the stratosphere in the tropics, J. Geophys. Res.-Atmos., 110, D08107, doi:10.10292004JD005516, 2005.

Gettelman, A., Randel, W. J., Wu, F., and Massie, S. T.: Transport of water vapor in the tropical tropopause layer, Geophys. Res. Lett., 29, 1009, doi:10.1029/2001GL013818, 2002.

Harris, J. M., Draxler, R. R., and Oltmans, S. J.: Trajectory model sensitivity to differences in input data and vertical transport method, J. Geophys. Res., 110, D14109, doi:10.1029/2004JD005750, 2005.

Hatsushika, H. and Yamazaki, K.: Interannual variations of temperature and vertical motion at the tropical tropopause associated with ENSO, Geophys. Res. Lett., 28, 2891-2894, 2001.

Hatsushika, H. and Yamazaki, K.: Stratospheric drain over Indonesia and dehydration within the tropical tropopause layer diagnosed by air parcel trajectories, J. Geophys. Res.-Atmos., 108, 4610, doi:10.1029/2002JD002986, 2003.

Holton, J. R. and Gettelman, A.: Horizontal transport and the dehydration of the stratosphere, Geophys. Res. Lett., 28, 2799-2802, 2001. 
Jackson, D. R., Methven, J., and Pope, V. D.: Transport in the lowlatitude tropopause zone diagnosed using particle trajectories, J. Atmos. Sci., 58, 173-192, 2001.

Jensen, E. and Pfister, L.: Transport and freeze-drying in the tropical tropopause layer, J. Geophys. Res., 109, D02207, doi:10.1029/2003JD004022, 2004.

MacKenzie, A. R. and Haynes, P. H.: The influence of surface kinetics on the growth of stratospheric ice crystals, J. Geophys. Res., 97, 8057-8064, 1992.

MacKenzie, A. R., Schiller, C., Peter, Th., Adriani, A., Beuermann, J., Bujok, O., Cairo, F., Corti, T., DiDonfrancesco, G., Gensch, I., Kiemle, C., Krämer, M., Kröger, C., Merkulov, S., Oulanovsky, A., Ravegnani, F., Rohs, S., Rudakov, V., Salter, P., Santacesaria, V., Stefanutti, L., and Yushkov, V.: Tropopause and hygropause variability over the equatorial Indian Ocean during February and March 1999, J. Geophys. Res., 111, D18112, doi:10.1029/2005JD006639, 2006.

Methven, J.: Offline Trajectories: Calculation and Accuracy, Technical Report 44, UGAMP, CGAM, Department of Meteorology, University of Reading, PO Box 243, Early Gate, Reading, RG6 6BB, 1997.

Newell, R. E. and Gould-Stewart, S.: A stratospheric fountain?, J. Atmos. Sci., 38, 2789-2796, 1981.

Pruppacher, H. R. and Klett, J. D.: Microphysics of Clouds and Precipitation, vol. 18 of Atmospheric and Oceanographic Sciences Library, Kluwer Academic Publishers, 2 edn., 1997.

Ren, C. and MacKenzie, A. R.: Cirrus Parametrization and the Role of Ice Nuclei, Q. J. R. Meteor. Soc., 131, 1585-1605, 2005.
Schiller, C., Afchine, A., Eicke, N., et al.: Ice particle formation and sedimentation in the tropopause region: a case study based on in-situ measurements of total water during POLSTAR1997, Geophys. Res. Lett., 26, 2219-2222, 1999.

Sherwood, S. C.: A stratospheric "drain" over the maritime continent, Geophys. Res. Lett., 27, 677-680, 2000.

Stefanutti, L., MacKenzie, A. R., Santacesaria, V., Adriani, A., Balestri, S., Borrmann, S., Khattatov, V., Mazzinghi, P., Mitev, V., Rudakov, V., Schiller, C., Toci, G., Volk, C. M., Yushkov, V., Flentje, H., Kiemle, C., Redaelli, G., Carslaw, K. S., Noone, K., and Peter, Th.: The APE-THESEO tropical campaign: an overview, J. Atmos. Chem., 48, 1-33, doi:10.1023/B:JOCH.0000034509.11746.b8, 2004.

Stohl, A.: The FLEXTRA Trajectory Model Version 3.0 User Guide, University of Munich, Am Hochanger 13, 85354 Freising, Germany, 1999.

Stohl, A., Haimberger, L., Scheele, M. P., and Wernli, H.: An intercomparison of results from three trajectory models, Meteorol. Appl., 8, 127-135, 2001.

Vomel, H. and Oltmans, S. J.: Comment on "A reexamination of the "stratospheric fountain" hypothesis" by A. E. Dessler, Geophys. Res. Lett., 26, 2737-2738, 1999.

Wernli, H. and Davies, H. C.: A Lagrangian-based analysis of extratropical cyclones .1. The method and some applications, Q. J. Roy. Meteor. Soc., 123, 467-489, 1997.

Zöger, M., Schiller, C., and Eicke, N.: Fast in-situ hygrometers: a new family of balloon-borne and airborne Lyman $-\alpha$ photofragment fluorescence hygrometers, J. Geophys. Res., 104, 1807$1816,1999$. 